\title{
Sustainability in the Curriculum and Teaching of Economics: Transforming Introductory Macroeconomics
}

\author{
Madhavi Venkatesan* \\ Department of Economics, Bridgewater State University, Bridgewater, MA USA \\ *Corresponding author: mvenkatesan@bridegw.edu
}

Received November 12, 2014; Revised December 31, 2014; Accepted January 04, 2015

\begin{abstract}
Present models of economic growth primarily focus on the role of expenditures as captured in the commonly cited economic indicator, gross domestic product (GDP), where GDP is defined as the sum of final goods and services sold within a country's natural borders. Noting that a country's expenditures are referred to as "aggregate expenditures" and that the majority of spending is specific to consumption or consumer spending, especially in the United States where this spending category is nearly two-thirds of annual GDP (other expenditure categories for GDP include investment spending, government spending and foreign spending as proxied by net exports), there exists a significant relationship between consumer expenditures and macroeconomic growth, justifying the standard acceptance of consumption-based expenditures as being a significant driver of economic expansion. Given the consumption and growth relationship, consumption values and behaviors have a significant impact on economic outcomes as well as other parameters including the environment and social and economic equity, where the latter are defined as relating to disparities between groups within a country, as well as across countries. Following a discussion of the impact of consumer-led growth on sustainability parameters: the environment, economic and social equity, this paper provides an explicit linkage between the measure of economic progress in universal use, GDP, and the degradation to common global resources, connecting the endogeneity present between the modeling of economic growth and the values and behaviors that support the outcome of the very same growth. A discussion of the present teaching methods specific to introductory macroeconomics provides the foundation for an innovative, replicable, and grant-funded case study for introducing sustainability. The curriculum variants discussed are not in widespread use and at present, there are no standard textbooks for the instruction of Principles of Macroeconomics that explicitly include sustainability and provide sustainability-based economic parameters for alternative evaluation to standard economic growth as presently and singularly enumerated in GDP. The value-augmenting outcome of the sustainability inclusive curriculum case study is captured in a qualitative assessment of student reaction and absorption of sustainability as a value and behavior catalyst and provided in summary form.
\end{abstract}

Keywords: curriculum, macroeconomics, economics

Cite This Article: Madhavi Venkatesan, "Sustainability in the Curriculum and Teaching of Economics: Transforming Introductory Macroeconomics.” American Journal of Educational Research, vol. 3, no. 1 (2015): 5-9. doi: 10.12691/education-3-1-2.

\section{Introduction}

Present models of economic growth primarily focus on the role of expenditures as captured in the commonly cited economic indicator, gross domestic product (GDP), where GDP is defined as the sum of final goods and services sold within a country's natural borders. Noting that a country's expenditures are referred to as "aggregate expenditures" and that the majority of spending is specific to consumption or consumer spending, especially in the United States where this spending category is nearly twothirds of annual GDP (other expenditure categories for GDP include investment spending, government spending and foreign spending as proxied by net exports), there exists a significant relationship between consumer expenditures and macroeconomic growth, justifying the standard acceptance of consumption-based expenditures as being a significant driver of economic expansion. Given the consumption and growth relationship, consumption values and behaviors have a significant impact on economic outcomes as well as other parameters including the environment and social and economic equity, where the latter are defined as relating to disparities between groups within a country, as well as across countries.

Following a discussion of the impact of consumer-led growth on sustainability parameters: the environment, economic and social equity, this paper provides an explicit linkage between the measure of economic progress in 
universal use, GDP, and the degradation to common global resources, connecting the endogeneity present between the modeling of economic growth and the values and behaviors that support the outcome of the very same growth. A discussion of the present teaching methods specific to introductory macroeconomics provides the foundation for an innovative, replicable, and grant-funded case study for introducing sustainability. The curriculum variants discussed are not in widespread use and at present, there are no standard textbooks for the instruction of Principles of Macroeconomics that explicitly include sustainability and provide sustainability-based economic parameters for alternative evaluation to standard economic growth as presently and singularly enumerated in GDP. The value-augmenting outcome of the sustainability inclusive curriculum case study is captured in a qualitative assessment of student reaction and absorption of sustainability as a value and behavior catalyst and provided in summary form.

\section{The Present State of Introductory Economics Instruction}

Principles of Macroeconomics is typically taught as one of a two part introductory requirement leading to the formal study of Economics and other undergraduate business majors. The course focuses on the aggregate factors that define economic progress as this concept relates to the "standard" expenditure-based variable of quantifying growth: gross domestic product (GDP). The course incorporates elements of Microeconomics to establish the foundation for the assumptions of individual and firm behavior where such behavior is guided by a "rational" agent assumption and the underlying premise of rational decision-making is defined as maximizing return while minimizing cost.

Costs are assumed to be priced through efficient market assumptions and are therefore simplified as being indicative of market pricing with limited consideration devoted to the potential for systemic under-enumeration of costs resulting from informational, regulatory, or exploited variations. Additionally consumption is not evaluated as a value that is enabled through pricing distortions, rather consumption, along with other expenditure components, investment, government spending, and net exports, are discussed as "given" parameters of economic growth.

As Nelson (1995) points out, economics evaluates efficiency with respect to the "use of resources to maximize production and consumption, not by the moral desirability of the physical methods and social institutions used to achieve this end." Therefore sustainability does not enter standard economic thinking. Reduction in consumption in the current period is only addressed through the lens of an increase in consumption in a later period. Nelson notes, "The possibility that consumption should be reduced because the act of consumption is not good for the soul, or is not what actually makes people happy, has no place within the economic value system.”

In their analysis of the teaching of the Principles of Macroeconomics, Knoedler and Underwood (2003) found that "the myopic teaching style of economics is attributable to both economic instructors and to the leading texts in use for the instruction of Principles of
Macroeconomics courses.” Furthermore, they state that the standard teaching of economics did not provide access to alternative approaches, for example, normative economics was found to be "demonstrated by a quick example as something to be avoided at all costs, unlike the exercise in positive economics."

The seeming lack of attention to values and behavior as captured within standard expenditure based macroeconomic modeling has distanced students from the tangibility of economics, limiting their understanding of the explanatory potential of economics and the application of economics as both a cause and a remedy of unsustainable practices. As noted by O'Hara (1995), understanding of economics is essential to sustainability and an understanding of the social and ecological context related to observable sustainability issues is requisite in the evaluation of a solution, "sustainability challenges us to recover the links between social and ecological contexts."

To the extent that economic growth has been and continues to be a national goal both within and without the United States, there is an inherent endogeneity between the current expenditure-based teaching of Principles of Macroeconomics and the observable natural resource degradation, and economic and social inequities. The focus on implicit consumption-led growth limits the potential for sustainability, as myopic consumer-led, immediate gratification-oriented growth (utility and profit maximization) as captured in the modeling of economic activity is inconsistent with the quantified evaluation of the externalities caused by production to meet consumption demand (Czech, 2000). Boran (2006) points out, albeit subtly, economic modeling is limited in its ability to adequately assess and address inequities that may arise as a result of standard economic analysis. Specifically, the increase in pollution that arises due to an inability to properly quantify the environmental burden of ambient emissions at a specific point in time.

The practice and teaching of economics, implicitly influences and reinforces consumption-led growth while contributing to the development of economic agent behavior. In turn, this learned economic literacy, in essence, contributes to the scientific approach to evaluating economic outcomes. Therefore, if the discipline does not include values and behavioral outcomes related to sustainability, it can be stated to be a contributing element of the present-day outcome of a lack of sustainability.

\section{Rationale for Explicit Integration of Sustainability in Economics}

The present multi-disciplinary emergence of sustainability is a result of anthropogenic attribution of the increasing speed of climate change and environmental degradation (Lovejoy, 2014). Adverse impacts to global resources may not have been properly noted or addressed during the most recent period of human-led environmental modification as defined by the period from the late $17^{\text {th }}$ century to the present. Further, the environmental impact presently observed, can be attributed to the myopic desire and attainability of human-centric, higher quality of life standards accessible through changing economic structures as addressed by early economists and political 
philosophers, Adam Smith and Jeremy Bentham. As noted by Nelson (1995), "the present shift from efficiency to sustainability no doubt reflects in part the moral disappointments of the twentieth century, relative to the hopes for economic progress that were widely shared at the beginning."

Efficiency has been simplified in economic modeling to account for "process efficiency," which through the most recent period has been evaluated as present costs relative to revenue generation. Costs articulated in standard evaluation have rarely been holistic or inclusive of nonquantifiable components to production; therefore, costs as described have not included items that were not readily quantifiable or were created as a result of natural resource utilization, degradation, or replenishment. Common assets such as water, air, and land were not included in production assessments; furthermore, damages resulting to any of these common elements were not articulated unless indirectly addressed as being a part of social and governmental regulation.

Anthropomorphic impacts related to production and consumption, inclusive of profit and utility maximization have been significant. To a large extent this is attributable to the lack of inclusion of the inter-relationship between the environment and human activity, as is captured in the concept of sustainability. Explicit attribution of sustainability in economics serves to increase awareness of the consumption and production linkage to the adverse externalities being currently faced, by also promoting, within a classroom setting, the endogeneity of values to economic outcomes. By focusing on the economic, social, and environmental outcomes from an expenditure-based view relative to the quality of life outcome attributable to a sustainability value paradigm, students are able to evaluate their own values, including the attribution of their personal values, and to then develop awareness of alternative value structures that promote balanced growth along the lines of economic equity, and social and environmental justice, all of which comprise the concept of sustainability.

\section{Principles of Macroeconomics: Sustainability Integration Case Study}

As part of a semester-long Principles of Macroeconomics course and following student introduction to basic macroeconomic concepts and related market mechanisms (movement along, shift of supply and demand; general understanding of consumption led growth, and the behaviors or values embodied within the framework of growth as it is currently defined and evaluated through GDP), students were introduced to the aggregate expenditure function ${ }^{1}$ and the explicit need for consumption in the evaluation of economic growth.

Following the introduction of the foundation of macroeconomic variables and concepts, students were

1 Aggregate expenditure function: $\mathrm{Y}=\mathrm{C}+\mathrm{I}+\mathrm{G}+(\mathrm{X}-\mathrm{M})$; where $\mathrm{Y}$ identifies the total amount expended in a given economy on goods and services over a given period; $\mathrm{C}$ is consumer expenditures, which in the United States accounts for two-thirds of $\mathrm{Y}$; I is investment spending attributable to businesses; $\mathrm{G}$ is government spending; and $(\mathrm{X}-\mathrm{M})$ is next exports and is reflective of foreign spending on domestic goods and services. asked to fill out a questionnaire, where the questionnaire focused on the student's understanding of the relationship between behaviors and economic outcomes through the lens of the values that were of significance to the student. Students were provided with the opportunity to comment on the rationale for the values expressed in their actions. The questionnaire did not directly address sustainability, though students were asked if they had taken a course in sustainability or that incorporated sustainability. Additionally questions were asked to assess the conspicuous consumption and social basis for consumption and expenditure behavior. The questionnaire as provided in the Appendix, provided a baseline for reviewing any changes in student value orientation as a result of the explicit introduction of sustainability.

Students were then introduced to the concept of consumerism and were made aware of the endogeneity between marketing, advertising, consumption, credit access, and GDP growth through detailed discussion of the aggregate expenditure function, as well as monetary and fiscal policy mechanisms. Using standard aggregate demand and supply models, students were introduced to the impact of excess demand on natural resource utilization, exploitation, and development; and were provided with an understanding of non-articulated and under-enumerated costs and asked to assess the benefits and costs of trade from both a profitability and environmental-social welfare perspective. Further, students were introduced to the role and purpose of the central bank and the government in the target goal of monetary and fiscal policy to maintain full employment as defined as the employment level consistent with the maximum aggregate expenditure level found at the optimal economy-wide production capacity (full production capacity) at a given point in time.

The process of instruction and assessment of sustainability factors related to the dependence of consumption on credit; trade and exploitable, quantifiable cost differentials; natural resource use and cost of degradation and replenishment; marketing and consumer demand; and the tragedy of the commons as related to the exploitation of common resources. All of the mentioned topics were addressed and evaluated as a class and on an individual student basis.

Weekly readings related to a macroeconomic topic and its sustainability correlate were assigned from a variety of sources, including popular press articles and a grant sponsored non-academic text selected specifically due to its retail target audience and its tangible examples related to predicted zero GDP growth levels due to both the lack and future need for sustainability practices.

Each week, four students were selected to be discussion group leaders, with a responsibility to facilitate weekly inclass sustainability focused discussion related to an aforementioned macroeconomic topic and corresponding readings. The group leaders were required to develop at minimum two questions (selected weekly questions are provided in the Appendix) specific to the macroeconomic and sustainability-based reading assignment for the week and the questions were distributed to all students one class period prior to scheduled class discussions. Students were expected to address all questions prior to class and to formally submit answers for two questions via an electronic journal. The questions, discussion, and journal 
entries were meant to provide students with an assessment of the role that implicit values have in individual decisionmaking and to increase awareness of how implicit social values impact individual consumption behavior and thereby eventually culminate in economic outcomes.

The integration of sustainability overlapped the standard course curriculum. Weekly sustainability topics followed and countered implicit values within the subject matter of the course, giving students an ability to understand the present macroeconomic phenomenon and then evaluate the same through a sustainability lens. The focus of macroeconomic and corresponding sustainability discussion was consumer-based consumption as an integral and targeted component of aggregate expenditures and corresponding GDP growth.

The students' weekly journals, discussion participation, and initial questionnaire submission provided a qualitative capture of the students' individual evolving and static economic values and behaviors. The responses detailed in these vehicles though the course of the semester were compared against the exit essay, which asked students to describe what change if any did a greater understanding of macroeconomic principles in conjunction with implicit consumerism and understanding of the need for sustainability values have on their individual consumption behavior and likely future behavior. The essay along with the chronology of responses was used to assess the impact to decision-making and economic rational agent creation, resulting from taking a course in introductory macroeconomics that incorporated sustainability.

\section{Values, Behaviors and Economic Outcomes: The Case for Integrating Sustainability}

The integration and assessment process described in this paper provides one example of explicit integration of sustainability in the introductory economics curriculum. Though not exhaustive in the mechanics implemented, the curriculum revision shared reflects an innovative approach to the introduction of sustainability in introductory economics curriculum. As noted the curriculum introduced in this paper incorporated a required selfassessment based journal. Student tracking of own-value led consumption behavior and the evolution of the value/behavior relationship through the course of the term, provided a qualitative assessment of the outcome of the introduction of sustainability to both values and related behaviors as well as the development of the student into a sustainable rational economic agent.

The results of the grant-based project indicate what would be expected, understanding of implicit values in conjunction with the global issues resulting from the same values fosters modification of behaviors, potentially culminating in the development of sustainable values and modified economic outcomes, as well as the potential for the establishment of revised and universally adopted metrics to assess economic growth.

Student discussions and responses provided clear evidence that as awareness of environmental issues including waste disposal and plastic use increase, modification of behavior in conjunction with an increased awareness of economic drivers such as, marketing, to both promote and align with consumption behaviors, and access to consumer credit, to promote inter-temporal consumption, can be augmented.

Concluding course student commentary included a cessation in the purchase of plastic bottles and use of recyclable and reusable containers, to reduction in the use of water for showers and daily hygienic activities, to an awareness of the adverse environmental, social justice, and credit impact of the purchase of excess clothing as a result of marketing induced need or want.

The underlying rationale for the introduction of sustainability in a Principles of Macroeconomics course was the premise that most individuals are not rational economic agents; rational economic agent behavior is created or taught through economic literacy, which can be considered as an implicit outcome of the introductory economics course objective. Rational agent behavior is defined as including an understanding and conscious incorporation of cost-benefit analysis (utility maximization) and other economics-based parameters in individual decision-making. As a result, most decision-making is fostered by limits that are consciously imposed, awareness of sustainability in consumption decisions can therefore, modify utility decisions by including the impact to the greater environmental good in consumption decisions. For example, in a consumer-oriented society, marketing and advertising as well as convenience drive behavior, where as, when the concept of holistic evaluation in decision making is presented, such that the individual thinks beyond just immediate consumption to incorporate the waste of consumption and the externalities resulting as a by-product of production-both of which are often either neglected or under-enumerated in price, consumption behavior can be augmented. Integration of explicitly stated sustainability-based alternatives influence values and resulting behaviors, culminating over time with societal traction to result in a modification in economic outcomes. The latter is the subject of the author's present research interests, which are focused on market inefficiency as a result of inappropriate categorizations of environmental resources as abundant rather than scarce.

\section{References}

[1] Bishop, R. C. (1993). "Economic Efficiency, Sustainability, and Biodiversity”. Ambio, Vol. 22, No. 2/3, 69-73.

[2] Boran, I. (2006). "Benefits, Intentions, and the Principle of Fairness”. Canadian Journal of Philosophy, Vol. 36, No. 1, 95-115.

[3] Dillard, D. (1982). "Rewriting the Principles of Economics". Journal of Economic Issues, Vol. 16, No. 2, 577-585.

[4] Choi, S. and Ng, A. (2011). "Environmental and Economic Dimensions of Sustainability”. Journal of Business Ethics, Vol. 104, No. 2, 269-282.

[5] Colander, D. (2005). "What Economists Teach and What Economists Do”. The Journal of Economic Education, Vol. 36, No. 3, 249-260.

[6] Czech, B. (2000). "Economic Growth as the Limiting Factor for Wildlife Conservation”. Wildlife Society Bulletin, Vol. 28, No. 1, 4-15.

[7] Fagg, J. (1981). “The Fundamental Principles of Economics”. Journal of Economic Issues, Vol. 15, No. 4, 937-942.

[8] Junyent, M. and Geli de Ciurana, A. M. (2008). "Education for Sustainability in University Studies: A Model for Reorienting the Curriculum”. British Educational Research Journal, 34:6, 763-782. 
[9] Knoedler, J. T. and Underwood, D. A. (2003). "Teaching the Principles of Economics: A Proposal for a Multi-Paradigmatic Approach”. Journal of Economic Issues, Vol. 37, No. 3, 697-725.

[10] O’Hara, S. U. (1995). "Sustainability: Social and Ecological Dimensions". Review of Social Economy, Vol. 53, No. 4, 529-551.

[11] Lovejoy, S. (2014). "Scaling Fluctuation Analysis and Statistical Hypothesis Testing of Anthropogenic Warming”. Climate Dynamics.

[12] Mayer, A.L., Thurston, H. W., and Pawlowski, C. W. (2004). "The Multidisciplinary Influence of Common Sustainability Indices”. Frontiers in Ecology and the Environment, Vol. 2, No. 8, 419-426.

[13] McKenzie, M., Williams, K. R., Weed, A. and Carroll, T. X. (2003). "Values, Transcendence, and Teaching: A Symposium". The Journal of General Education, Vol. 52, No. 1, 1-26.

[14] Neal, P. (1988). "Hobbes and Rational Choice Theory". The Western Political Quarterly, Vol. 41, No. 4, 635-652.

[15] Nelson, R.H. (1995). "Sustainability, Efficiency, and God: Economic Values and the Sustainability Debate”. Annual Review of Ecology and Systematics, Vol. 26, 135-154.

[16] Passerini, E. (1998). "Sustainability and Sociology". The American Sociologist, Vol. 29, No. 3, 59-70.
[17] Peterson-Boring, W. (2010). "Sustainability and the Western Civilization Curriculum: Reflections on Cross-pollinating the Humanities and Environmental History”. Environmental History, Vol. 15, No. 2, 288-304.

[18] Shah, M. (1999). "Synthesis of Ecology and Economics: Towards a New Theoretical Paradigm”. Economic and Political Weekly, Vol. 34, No. 46/47, 3293-3298.

[19] Som, C., Hilty, L.M., and Köhler, A.R. (2009). "The Precautionary Principle as a Framework for a Sustainable Information Society”. Journal of Business Ethics, Vol. 85, 493505.

[20] Wetzel, J.N., Potter, W. J., and O'Toole, D. M. (1982). "The Influence of Learning and Teaching Styles on Student Attitudes and Achievement in the Introductory Economics Course: A Case". The Journal of Economic Education, Vol. 13, No. 1, 33-39.

[21] Xiao, Y., Faff, R., Gharghori, P., and Lee, D. (2013). "An Empirical Study of the World Price of Sustainability". Journal of Business Ethics, Vol. 114, No. 2, 297-310.

[22] Zsolnai, L. (2007). "Western Economics versus Buddhist Economics”. Society and Economy, Vol. 29, No. 2, 145-153. 